\title{
ESQUISTOSSOMOSE MANSONI EXPERIMENTAL. CARGA PARASITÁRIA E DISTRIBUIÇÃO DE VERMES ADULTOS NO SISTEMA PORTA DE RATOS ALBINOS TRATADOS COM AZATIOPRINA
}

\author{
Carlos Alberto Moreira Campos
}

\begin{abstract}
Estudou-se o curso da infecção esquistossomótica experimental no rato albino, um hospedeiro singular para o Schistosoma mansoni, e quatro semanas após a infecção houve uma rápida diminuição na carga parasitária, fato esse denominado por alguns pesquisadores como "fenômeno de autocura". Contudo, após a administração de um imunossupressor - a Azatioprina - observou-se uma maior susceptibilidade dos ratos à infecção, com os animais apresentando um significativo retardamento no chamado "fenômeno de autocura". A grande maioria dos vermes é recuperada nos vasos intra-hepáticos do sistema porta, sem que haja migração para as veias mesentéricas. Quando os ratos foram tratados com Azatioprina observou-se uma significativa localização mesentérica dos vermes adultos neste hospedeiro.
\end{abstract}

Palavras chaves: Schistosoma mansoni. Esquistossomose experimental. Imunossupressão.

Dentre os roedores usualmente empregados no estudo da esquistossomose mansoni experimental, o rato albino é o menos sensível ao parasito, apresentando aspectos que o distingue de outros animais de laboratório, como camundongos e hamsters ${ }^{7}$. Sabe-se que as cercárias penetram em sua pele com a mesma eficácia mostrada para os animais sensíveis ${ }^{8}$, mas cerca da metade morre in situ dez minutos após a penetração. A recuperação de vermes adultos através de perfusão, quatro semanas após a infecção, varia entre cinco e $30 \%$, sendo a cinética da infecção bastante influenciada pela idade dos animais ${ }^{5}$. A partir da quarta semana scgue-se uma rápida diminuição no número de esquistossomos recuperados, fenômeno esse denominado por alguns pesquisadores como "autocura" do animal ${ }^{2}$. Além dessa "autocura", o limitado número de vermes que sobrevive no rato é recuperado nos vasos intra-hepáticos do sistema porta, sendo praticamente nulo o número dos que migram para as ramificações mesentéricas do roedor. Esses

Realizado pelo Grupo Interdepartamental de Estudos Sobre Esquistossomose (GIDE), ICB, Universidade Federal de Minas Gerais.

Endereço para correspondência: Departamento de Biologia do Centro de Biociências da Universidade Federal do Rio Grande do Norte, Campus Universitário, 59000 Natal, RN.

Recebido para publicação em 6/4/83. vermes não se desenvolvem até o seu tamanho normal e produzem pouquíssimos ovos, quase sempre inférteis ${ }^{6}$. A "autocura" do rato tem sido enfocada como sendo de natureza imunológica. Cioli e Dennert ${ }^{2}$ usando meios imunossupressores drásticos, como timectomia e irradiação, observaram uma maior susceptibilidade dos ratos assim tratados, com os animais apresentando uma maior carga parasitária.

O presente estudo visa observar a ação de uma droga imunossupressora, a Azatioprina, no curso da infecção esquistossomótica do rato albino, no intuito de estabelecer possiveis modificações quanto à "autocura" e na distribuição do $S$. mansoni no sistema porta desse roedor submetido a uma imunossupressão química.

\section{MATERIAL E MÉTODOS}

Em todos os experimentos foram utilizadas cercárias da cepa LE (Belo Horizonte), mantidas em Biomphalaria glabrata do moluscário do GIDE (ICB-UFMG). A infecção dos roedores foi feita por via subcutânea, com cerca de 500 cercárias. Os animais, tanto do grupo experimental quanto do grupo controle, foram ratos albinos de ambos os sexos, com cerca de 40 dias de vida e pesando entre 100 e 200 gramas. Esses ratos não tinham linhagem genética conhecida. 
A droga usada como supressora da resposta imune foi a Azatioprina (AZT), que é um derivado imidazólico da mercaptopurina. A dose administrada foi do $38 \mathrm{mg} / \mathrm{kg}$, por via subcutânea, com tratamento iniciado três dias antes da exposição dos animais, repetido a cada três dias e prolongando-se até a necropsia dos ratos, de acordo com o trabalho de Campos ${ }^{1}$.

A recuperação dos esquistossomos foi feita aos 25 e 38 dias após a infecção, pela técnica de perfusão descrita por Pellegrino e Siqueira ${ }^{4}$. Os vermes recuperados foram desenhados e medidos.

A avaliação da supressão das respostas celular e humoral do rato foi feita, respectivamente, pelos testes de inchação das patas ("footpad swelling") e hemaglutinação. Todos os resultados foram submetidos à análise estatistica para verificação da significância.

\section{RESULTADOS}

Os resultados apresentados na Tabela 1 mostram o efeito do tratamento imunossupressor, com AZT na dose de $38 \mathrm{mg} / \mathrm{kg}$, sobre a carga parasitária. Assim, observa-se que na perfusão feita para controle da infecção (250 dia) há uma média alta de esquistossomos recuperados, tanto para o grupo experimental (Grupo A) quanto para o controle (Grupo B).

Tabela 1 - Efeito do tratamento com AZT na dose de $38 \mathrm{mg} / \mathrm{kg}$ sobre a recuperação de vermes, com o tratamento iniciado três dias antes da infecção dos animais.

\begin{tabular}{|c|c|c|c|c|c|c|c|}
\hline Grupo & $\begin{array}{c}N \text { de de } \\
\text { ratos }\end{array}$ & $\begin{array}{l}\text { Dias de } \\
\text { infecçãoo }\end{array}$ & Média & $\begin{array}{l}d e \\
\pm \quad 1\end{array}$ & $\begin{array}{l}\text { vermes } \\
P\end{array}$ & $\begin{array}{c}\% \text { de } \\
\text { recuperação }\end{array}$ & $p$ \\
\hline A & 10 & 25 & 48,1 & \pm & 27,9 & 9,6 & \multirow[t]{2}{*}{ NS } \\
\hline B & 10 & 25 & 42,2 & \pm & 28,1 & 8,4 & \\
\hline A & 11 & 38 & 15,6 & \pm & 11,7 & 3,1 & \multirow{2}{*}{0,05} \\
\hline B & 11 & 38 & 5,7 & \pm & 5,1 & 1,1 & \\
\hline
\end{tabular}

DP - Desvio padrão

Grupo A - Tratado com AZT na dose de $38 \mathrm{mg} / \mathrm{kg}$

Grupo B - Controle

NS - Não significativo

Entretanto, na recuperação feita no 38 ? dia (controle da "autocura"), observa-se que a carga parasitária do Grupo A (experimental) é cerca de três vezes maior que a do Grupo B (controle), sendo estatisticamente bastante significante $(\mathrm{p}<0,05)$.

A Tabela 2 mostra o efeito do tratamento imunossupressor na migração dos vermes, onde - aos 25 dias - observou-se um número semelhante de vermes nas diferentes localizações. Contudo, na perfusão feita aos 38 dias encontrou-se um número significativamente maior de vermes recuperados nos vasos mesentéricos dos animais do grupo tratado $(\mathrm{p}<0,05)$, mostrando que houve uma migração de vermes dos vasos intra-hepáticos do sistema porta para os vasos mesentéricos. 
Campos CAM. Esquistossomose Mansoni experimental. Carga parasitária e distribuiçẫo de vermes adultos no sistema porta de ratos albinos tratados com azatioprina. Revista da Sociedade Brasileira de Medicina Tropical 16:154-157, Jul/Set, 1983

Tabela 2 - Efeito do tratamento com AZT na dose de $38 \mathrm{mg} / \mathrm{kg}$ sobre a migração de esquistossomos para os vasos mesentéricos. Tratamento iniciado três dias antes da infecção dos animais.

\begin{tabular}{|c|c|c|c|c|c|c|}
\hline Grupo & $\begin{array}{l}\text { No de } \\
\text { ratos }\end{array}$ & $\begin{array}{l}\text { Dias de } \\
\text { infecçãoo }\end{array}$ & & $\begin{array}{l}\text { zção } \\
\text { mes }\end{array}$ & $\begin{array}{cc}\% & \text { de } \\
\text { recuperação }\end{array}$ & $p$ \\
\hline \multirow[t]{3}{*}{ A } & 10 & 25 & $\mathrm{~F}$ & 477 & 9,54 & \\
\hline & & & M & 4 & 0,08 & \\
\hline & & & $\mathrm{P}$ & 0 & 0,00 & NS \\
\hline \multirow[t]{3}{*}{ B } & 10 & 25 & $\mathrm{~F}$ & 418 & 2,83 & \\
\hline & & & M & 0 & 0,00 & \\
\hline & & & $\mathbf{P}$ & 4 & 0,08 & \\
\hline \multirow[t]{3}{*}{ A } & 11 & 38 & F & 156 & 2,83 & \\
\hline & & & M & 16 & 0,29 & \\
\hline & & & $\mathbf{P}$ & 0 & 0,00 & 0,05 \\
\hline \multirow[t]{3}{*}{ B } & 11 & 38 & F & 62 & 1,12 & \\
\hline & & & M & 1 & 0,02 & \\
\hline & & & $\mathbf{P}$ & 0 & 0,00 & \\
\hline
\end{tabular}

Grupo A - Tratado com AZT na dose de $38 \mathrm{mg} / \mathrm{kg}$

Grupo B - Controle

F - Vasos intra-hepáticos

M - Vasos mesentéricos

P - Veia porta

NS - Não significativo

\section{DISCUSSÃO}

Cioli e Dennert ${ }^{2}$, usando meios imunossupressores bastante drásticos - timectomia e irradiação -, conseguiram uma maior carga parasitária no grupo assim tratado, estabelecendo que o fenômeno é, em parte, de natureza imunológica e timodependente. No presente trabalho usou-se como agente imunossupressor um análogo da purina, a Azatioprina (AZT), com o qual conseguiram-se resultados semelhantes aos encontrados pelos autores acima citados.

A AZT é um imunossupressor potente indicado em cirurgias de transplantes, onde favorece a sobrevivência e o funcionamento do órgão transplantado, e em algumas doenças autoimunes como o lupus eritematoso disseminado e a artrite reumatóide grave, com efeitos apreciáveis. Como antimetabólito, a AZT age bloqueando a proliferação celular, sendo especialmente tóxica para células que se dividem rapidamente, como as de tumores, da medula óssea, etc, atacando também linfócitos que proliferam em resposta a uma estimulação antigênica ${ }^{3}$.
A AZT na dose de $38 \mathrm{mg} / \mathrm{kg}$, repetida a cada três dias e com tratamento sendo prolongado até a necropsia dos animais, mostrou-se capaz de alterar a rejeição da infecção esquistossomótica do rato, retardando o fenômeno de "autocura" e propiciando uma maior migração de vermes do fígado para as veias mesentéricas. Como é conhecido da própria biologia do $S$. mansoni no rato ${ }^{6}$, os esquistossomos dificilmente fazem tal migração, concentrando-se em sua maioria no fígado do animal. Embora os mecanismos que impedem ou os que possibilitam tal evento sejam desconhecidos, parece realmente haver um envolvimento imunológico, uma vez que os animais imunossuprimidos apresentaram maior número de vermes em localização mesentérica, comparado com os animais do grupo controle. Tal fato dificilmente poderia ser atribuido à ação direta da droga sobre o verme adulto, uma vez que o fenômeno usualmente observado na quimioterapia da esquistossomose é justamente o contrário, isto é, migração de vermes dos vasos venosos mesentéricos para as ramificações intra-hepáticas da veia porta, após administração de um composto ativo. Se a resposta imunitária do rato ao $S$. mansoni permite que os vermes permaneçam no 
fígado (nos animais bons hospedeiros eles somente migram dos vasos venosos do fígado para os vasos mesentéricos após a maturidade sexual) e se a imunossupressão os "libertam", é ainda problema a ser esclarecido.

E possível que a imunossupressão com AZT seja menos eficaz que a usada por Cioli e Dennert ${ }^{2}$, contudo deve-se levar em conta que os animais usados neste experimento eram heterozigóticos, sem linhagem genética conhecida. Por outro lado, o modelo de imunossupressão aqui usado tem a vantagem de poder ser interrompido a qualquer tempo do trabalho, sendo um meio reversível de imunossupressão.

\section{CONCLUSÕES}

Os experimentos realizados neste trabalho permitem concluir que:

19) é possível interferir no processo de rejeição da infecção esquistossomótica desenvolvida pelo rato albino ("autocura") através de um imunossupressor químico;

29) nos ratos albinos imunossuprimidos observou-se uma maior migração de esquistossomos dos vasos intra-hepáticos para as ramificações mesentéricas;

39) a AZT suprime, aplicada a cada três dias, tanto a resposta celular quanto a humoral;

49) não se observou influência da droga sobre o tamanho dos vermes, apresentando-se estes com crescimento desordenado e predominando o número de vermes pequenos;

59) o presente trabalho confirma experimentos anteriores sobre o papel do sistema imunitário no fenômeno de "autocura" da infecção esquistossomótica do rato, mediante uma abordagem diferente.

\section{SUMMARY}

The course of experimental Schistosoma mansoni infection in the albino rat, a singular host for schistosomes was studied. Four weeks after infection there was a decrease of worm burden, a self-cure phenomenon reported by other investigators. However, after administration of a immunosupressive drug - Azathioprine - an increase in susceptibility of rats to infection was observed, with the animals presenting a significant delay in the to period self-cure. The majority of worms were recovered from the intra-hepatic veins of the portal system, but there was no migration to mesenteric veins. When rats were treated with Azathioprine a significant mesenteric localization of schistosomes was observed in this host.

Key words: Schistosoma mansoni. Experimental schistosomiasis. Immunosupression.

\section{REFERÊNCIAS BIBLIOGRÁFICAS}

1. Campos CAM. Efeitos do tratamento imunossupressor com azatioprina sobre a infecção esquistossomótica experimental do rato albino (Rattus norvegicus norvegicus). Tese de mestrado. Universidade Federal de Minas Gerais, Belo Horizonte, 1978.

2. Cioli D, Dennert G. The course of Schistosoma mansoni infection in thymectomized rats. The Journal of Immunology 117:59-65, 1976.

3. Davis DB, Dulbecco R, Eisen HN, Ginsberg HS, Wood HB. Microbiology Harper \& Row, London, 1973.

4. Pellegrino J, Siqueira AF. Técnica de perfusão para colheita de Schistosoma mansoni em cobaias experimentalmente infestadas. Revista Brasileira de Malariologia e Doenças Tropicais 8: 589-597, 1956.

5. Phillips SM, Colley DG. Immunologic aspects of the host responses to schistosomiasis: resistence, immunopathology and eosinophil involvement. Progress in Allergy 24:49, 1978.

6. Ritchie LS, Garson S, Knigth WB. The biology of Schistosoma mansoni in laboratory rats. The Journal of Parasitology 49:571-577, 1963.

7. Stirewalt MA, Hackey JR. Penetration of host skin by cercariae of Schistosoma mansoni. I - Observed entry into skin of mouse, hamster, rat, monkey and man. The Journal of Parasitology 42: 565-580, 1956.

8. Warren KS, Peters PA. Comparison of penetration and maturation of Schistosoma mansoni in hamsters, mouse, guinea pig, rabbit and rat. The American Journal of Tropical Medicine and Hygiene 16:718$-722,1967$. 